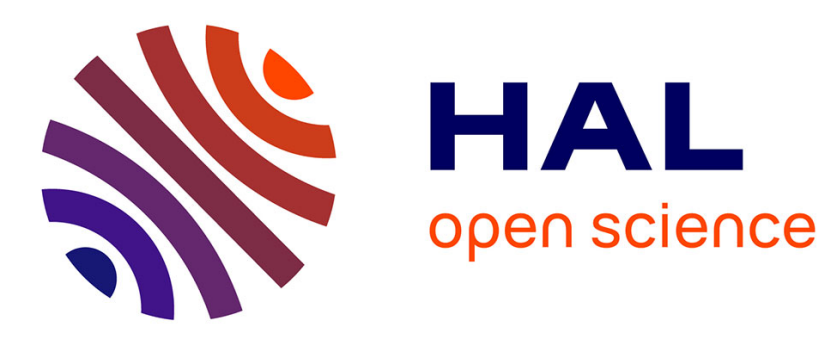

\title{
Structural Change of Calcium Silicate, a New Type of Desulfurization Material, Studied by Si K Edge XAFS
}

T. Tanaka, S. Yoshida, R. Kanai, T. Shishido, H. Hattori, Y. Takata, N.

Kosugi

\section{- To cite this version:}

T. Tanaka, S. Yoshida, R. Kanai, T. Shishido, H. Hattori, et al.. Structural Change of Calcium Silicate, a New Type of Desulfurization Material, Studied by Si K Edge XAFS. Journal de Physique IV Proceedings, 1997, 7 (C2), pp.C2-913-C2-914. 10.1051/jp4:1997278 . jpa-00255361

\section{HAL Id: jpa-00255361 https://hal.science/jpa-00255361}

Submitted on 1 Jan 1997

HAL is a multi-disciplinary open access archive for the deposit and dissemination of scientific research documents, whether they are published or not. The documents may come from teaching and research institutions in France or abroad, or from public or private research centers.
L'archive ouverte pluridisciplinaire HAL, est destinée au dépôt et à la diffusion de documents scientifiques de niveau recherche, publiés ou non, émanant des établissements d'enseignement et de recherche français ou étrangers, des laboratoires publics ou privés. 


\title{
Structural Change of Calcium Silicate, a New Type of Desulfurization Material, Studied by Si K Edge XAFS
}

\author{
T. Tanaka, S. Yoshida, R. Kanai*, T. Shishido*, H. Hattori*, Y. Takata** and N. Kosugi** \\ Department of Molecular Engineering, Kyoto University, Kyoto 606-01, Japan \\ * Center for Advanced Research of Energy Technology, Hokkaido University, Sapporo 060, Japan \\ ** Institute for Molecular Science, Myodaiji, Okazaki 444, Japan
}

\begin{abstract}
CaSiO}_{3}$ was found to be a material effective for deSOx in the presence of NO. The material is promising for the solution of environmental problems of exhaust gas from power station. $\mathrm{SO}_{2}$ was removed as $\mathrm{CaSO}_{4}$, involving oxidation of sulfur, accompanied by reduction of NO. After use as a deSOx reagent, it is confirmed that calcium ions become sulfate form but it has been difficult to examine what form silicon atoms are stanilized as. $Q^{2}$ silicon in metasilicate chain may be broken by absorption of SOx and it is expected that it changes to $Q^{4}$ silicon as a silica. However, there has been no direct evidence. In the present work, we recorded Si Kedge XAFS of $\mathrm{CaSiO}_{3}$ before and after use at UVSOR, Okazaki, Japan. The XANES spectra suggested the formation of $Q^{4}$ silicon, possibly, forming so-called silica.
\end{abstract}

\section{INTRODUCTION}

$\mathrm{CaSiO}_{3}$ was found to be a material effective for deSO $x$ in the presence of NO. [1] The material is promising for the solution of environmental problems of exhaust gas from power stations. $\mathrm{SO}_{2}$ was removed as $\mathrm{CaSO}_{4}$, involving oxidation of sulfur, accompanied by reduction of NO. Ideally, the reaction (desulfurization) proceeds like;

$$
\mathrm{CaSiO}_{3}+\mathrm{SO}_{2}+\mathrm{NO} \longrightarrow \mathrm{CaSO}_{4}+1 / 2 \mathrm{~N}_{2}+\mathrm{SiO}_{2}
$$

After use as a deSOx reagent, it is confirmed that calcium ions become sulfate form but it has been difficult to examine what form silicon atoms are stabilized as. It is naturally speculated that silicon ions are present as so-called silica as expressed in equation (1). However, all of the calcium ions are not consumed after passing the gas. Calcium silicate is known to have $\mathrm{Ca}_{1-x} \mathrm{H}_{2 x} \mathrm{SiO}_{3}$ form. Therefore, some of calcium ions should be left as a calcium hydrosilicate as shown in equation (2) or (3).

$$
\begin{array}{lll}
\left(\mathrm{CaSiO}_{3}\right)_{n}+\mathrm{SO}_{2}+\mathrm{H}_{2} \mathrm{O}+1 / 2 \mathrm{O}_{2} & \longrightarrow \mathrm{CaSO}_{4}+\left(\mathrm{Ca}_{1-i / n} \mathrm{H}_{2 / n} \mathrm{SiO}_{3}\right)_{n} \\
\left(\mathrm{CaSiO}_{3}\right)_{n}+\mathrm{SO}_{2}+\mathrm{H}_{2} \mathrm{O}+\mathrm{NO} & \longrightarrow \mathrm{CaSO}_{4}+\left(\mathrm{Ca}_{1-1 / n} \mathrm{H}_{2 / n} \mathrm{SiO}_{3}\right)_{n}+1 / 2 \mathrm{~N}_{2}
\end{array}
$$

Since the removal amount of $\mathrm{NO}$ is always smaller than that of $\mathrm{SO}_{2}$, oxidation by gaseous oxygen expressed in equation (2) was suggested. In any case, Si NMR is often used to examine the state of silicon. However, Si NMR study does not give the clear information, i.e., many intermediate resonance lines make it difficult to identify the silicate forms. Either, the $\mathrm{X}$-ray diffraction technique can not be applied to the sample of amorphous.

Calcium silicate involves metasilicate chains $\left(\mathrm{SiO}_{3}\right)_{n}^{2 n-}$ which has a $\mathrm{SiO}_{4}$ unit possessing two terminal oxygens and two bridging oxfgens. Calcium ions are located around the chain surrounded by some water molecules. Although some of the calcium ions are removed, protons can be in place of calcium for the compensation of charge balance to maintain metasilicate chain. Therefore, it has been difficult to examine the phase transition from metasilicate to other phase such as orthosilicate found in silica. In the present work, we recorded $\mathrm{Si} \mathrm{K}$ edge XAFS of $\mathrm{CaSiO}_{3}$ before and after use as the deSOx material to investigate the structural change around silicon atoms.

\section{EXPERIMENTAL}

\subsection{Desulfurization}

The calcium silicate sample $(500 \mathrm{mg})$ supplied from Wako Pure Chemical Co. was placed in a differential reactor maintained at $403 \mathrm{~K}$. A mixture gas $\left(\mathrm{SO}_{2} 1000 \mathrm{ppm}\right.$, NO $1000 \mathrm{ppm}, \mathrm{O}_{2} 10 \%, \mathrm{H}_{2} \mathrm{O} 10 \%$ and He for balance) was passed through the reactor and the composition of outlet gas was analyzed. In the first $80 \mathrm{~min}, 100 \%$ of $\mathrm{SO}_{2}$ was removed and the removal rate decreased gradually. The removal rate of NO was always lower than that of NO. At 5 h on stream, $24 \%$ of $\mathrm{SO}_{2}$ was removed. After 5 $\mathrm{h}$ gas passing, total molar amount of removed $\mathrm{SO}_{2}$ corresponded to $60 \%$ of calcium ions included in the original sample. 


\subsection{X-Ray absorption}

XAFS experiment was carried out at BL-1A at UVSOR (ring energy 750 $\mathrm{MeV}$ and stored current $190-150 \mathrm{~mA}$ ) at the institute for Molecular Science, Okazaki, Japan, with an InSb(111) double crystal monochromator. The powder sample was mounted on a scratched $\mathrm{Cu}$ plate placed under high vacuum $\left(<10^{-7}\right.$ Torr $)$. The signal was measured as a photocurrent. The incident photon intensity was measured as photocurrent rising from $\mathrm{Au}$ mesh which permits approximately $80 \%$ of $\mathrm{X}$-ray transmission.

The XAFS spectra were normalized as described elsewhere [2]. In this procedure, error in the normalized intensity was estimated to be within $6 \%$. The deconvolution of the XANES spectrum was carried out successfully with a single arctangent for a continuum absorption and Gaussians for resonance absorption. The use of Lorenzians did not give a satisfactory fit.

\section{RESULTS AND DISCUSSION}

Figure 1 shows the normalized XANES spectra of the sample before and after use for desulfurization accompanied with that of amorphous silica. Each spectrum shows the similar feature and sharp and a prominent peak found at around $11 \mathrm{eV}$. The peak for $\mathrm{CaSiO}_{3}$ virgin sample is much broader than that for silica and it gets sharper by passing the gas as shown in Fig. 1 (b). This sharp and intense absorption is possibly due to atomic-like Si $1 s$ to $3 p$ transition. In case of silica, a silicon atom is located at a center of the regular tetrahedron of oxygen atoms. Therefore, Si $3 p$ orbitals should be degenerated resulting in such a sharp absorption. The deconvolution of the spectrum with Gaussians showed that the full width at half maximum (FWHM) was $1.99 \mathrm{eV}$. On the other hand, for this absorption found in the spectrum of $\mathrm{CaSiO}_{3}$ virgin sample, FWHM was estimated to be more than $2.8 \mathrm{eV}$. The use of two Gausians gave the more satisfactory fit in the deconvolution procedure. Therefore, this suggests that the broadness of the peak is caused by the split of energy level of $\mathrm{Si} 3 \mathrm{p}$ orbitals in $\mathrm{CaSiO}_{3}$ virgin sample. The silicon atom in metasilicate chain has two kinds of Si-O bonds, resulting in the split of 3 p orbitals. This peak is sharpened in the spectrum of $\mathrm{CaSiO}_{3}$ sample after use. Hence, we can propose that $\mathrm{SiO}_{4}$ unit got close to a regular tetrahedron by the gas passing or silica partly appeared in the sample.

In any case, $5 \mathrm{~h}$ gas passing does not change all calcium ions from silicate to sulfate. Therefore, $\mathrm{CaSiO}_{3}$ sample after use should be a mixture and must include $\mathrm{CaSiO}_{3}$ phase. Therefore, we have attempted to subtract the spectrum of $\mathrm{CaSiO}_{3}$ virgin sample from $\mathrm{CaSiO}_{3}$ sample after use multiplied by a pertinent weight. Figure 2 shows the difference spectrum with a subtraction weight of 0.5 . Evidently, the spectrum is identical with that of silica, suggesting that $50 \%$ of silicon in the sample after use is stabilized as silica. This is well consistent with the value of the percentage of calcium ions which was changed to sulfate. The result indicates that consumption of $\mathrm{SO}_{2}$ gas by the calcium silicate sample is accompanied by the formation of silica. Although the reaction is enhanced by the presence of water suggesting the presence of the reaction path (2) or (3), we conclude that hydrosilicate form is not stable and the silicate chains changes easily to the 3-dimensional network of silicate to form so-called silica.

\section{Acknowledgments}

This work was supported by the Joint Studies Program (1994 - 1995) of the Institute for Molecular Science.

\section{References}

[1] Hattori H., Kanuka N., Kanai R., unpublished result.

[2] Tanaka T., Yamashita H., Tsuchitani R., Funabiki T., Yoshida S., J .Chem. Soc., Faraday Trans. I 8 4 (1988) 2987-2999.

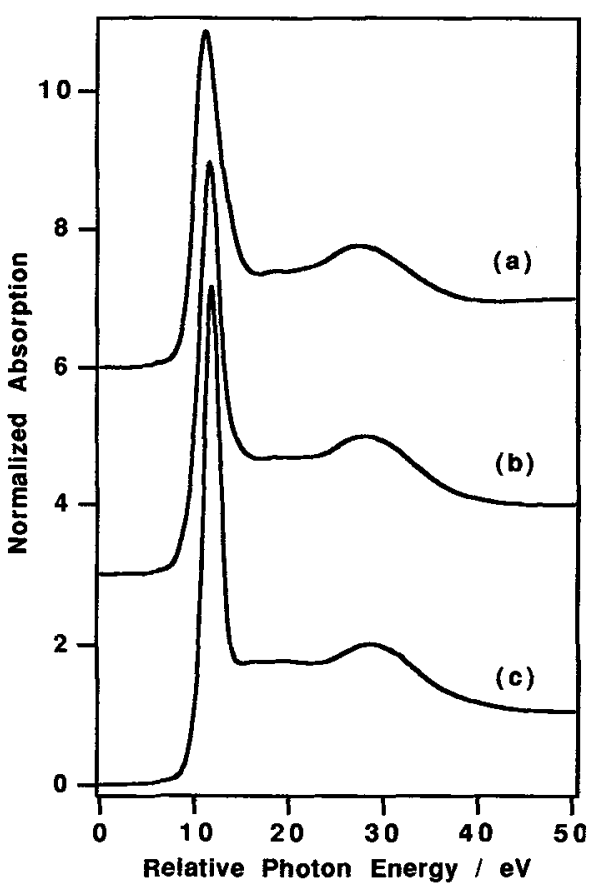

Figure 1: Normalized Si K-edge XANES spectra of (a) $\mathrm{CaSiO}_{3}$ before use, (b) $\mathrm{CaSiO}_{3}$ after use and (c) amorphous $\mathrm{SiO}_{2}$. Energy offset is taken to be $1835 \mathrm{eV}$.

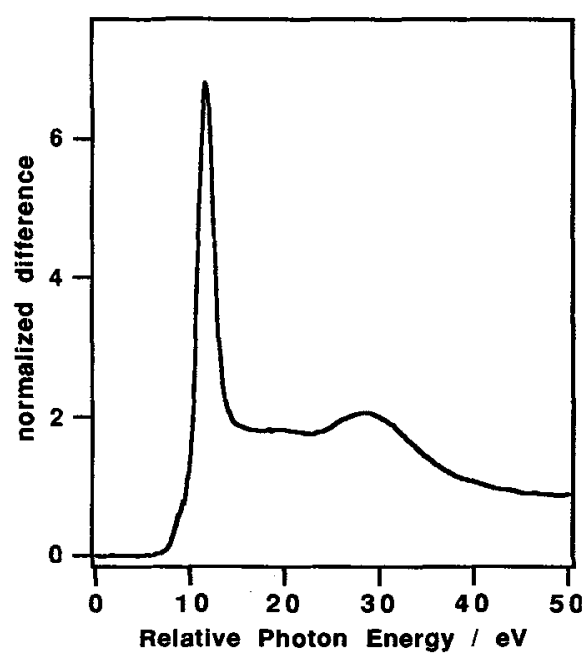

Figure 2 : Difference spectrum. ( (b) $-0.5 \times(a)) /$ 0.5 . (a), (b), see captions to Fig. 1 . 